\title{
Personal \& Professional Qualities of Medical Representative and Impact on Doctor's Prescribing Behavior
}

\author{
Vishavadia Krunal $^{1, *}$, Seema Singh $^{2}$, Sandip Solanki $^{3}$ \\ ${ }^{1}$ Gujarat Technological University, Ahmedabad, India \\ ${ }^{2}$ Symbiosis Centre for Corporate Education, Symbiosis International (Deemed University), Pune, Maharashtra, India \\ ${ }^{3}$ Symbiosis Institute of International Business (SIIB), Symbiosis International (Deemed University) (SIU), Hinjewadi, Pune, \\ Maharashtra, India
}

Received July 10, 2021; Revised November 8, 2021; Accepted November 25, 2021

\section{Cite This Paper in the following Citation Styles}

(a): [1] Vishavadia Krunal, Seema Singh, Sandip Solanki, "Personal \& Professional Qualities of Medical Representative and Impact on Doctor's Prescribing Behavior, "Universal Journal of Public Health, Vol. 9, No. 6, pp. 385 - 391, 2021. DOI: 10.13189/ujph.2021.090605.

(b): Vishavadia Krunal, Seema Singh, Sandip Solanki (2021). Personal \& Professional Qualities of Medical Representative and Impact on Doctor's Prescribing Behavior. Universal Journal of Public Health, 9(6), 385 - 391. DOI: 10.13189/ujph.2021.090605.

Copyright $\bigcirc 2021$ by authors, all rights reserved. Authors agree that this article remains permanently open access under the terms of the Creative Commons Attribution License 4.0 International License

\begin{abstract}
Background: The promotion of a pharmaceutical product is based on the effective collaboration between medical representatives (MR) \& physicians. Pharmaceutical companies are following many doctor-consulting strategies and have found a way to promote their products through MR. But it's only possible if the MR communicates the brand's benefit effectively to the doctor. Aims and Objectives: To identify the personal and professional qualities of MRs that affect doctors' prescribing behavior. The impact of three variables like product detailing of MR, MR's attire, and MR's knowledge has been measured on doctor's prescription behavior. Methodology: Three personal and/or professional qualities of MR have been identified (effective detailing, personal attire, and scientific knowledge of MRs) and studied the influence of these qualities on physician's prescribing habits. Responses were collected through self-administered questionnaires from general practitioners, physicians, gynecologists, pediatricians, and dentists. ANOVA \& regression analysis models were used to analyze the hypothesis. Result: Eighty-seven percent of the doctors agreed that pharmaceutical companies should train MRs properly about the detailing of brand and product knowledge, $64 \%$ of doctors agreed-upon personal attire of MRs attract their attention, and 92\% agreed that MR knowledge plays a crucial role in influencing their
\end{abstract}

prescribing behavior. The hypothesis was accepted for detailing, personal attire, and scientific understanding of MRs regarding their influence on doctor's prescription. Conclusion: The role of detailing, personal attire, and scientific knowledge of MR is well established to influence the practice of physicians. Pharmaceutical companies should train their sales team properly, starting from personal grooming to every aspect of brand and therapy for practical in-clinic discussion and doctor conversion.

Keywords Pharmaceutical Marketing, Medical Representative, Detailing, Pharmaceutical Companies

\section{Introduction}

Medical representatives (MRs) hold good marketing knowledge with communication skills, convincing power, advanced marketing strategies and work as a mediator between pharmaceutical companies and health care professionals [1].

Pharmaceutical companies appoint them to a defined area to visit physicians, chemists, and stockists. MRs, who form the backbone of pharmaceutical marketing, meet with physicians to influence the patterns of prescription 
drugs for their promoted brand [2].

Pharmaceutical companies use different strategies and tactics to convince doctors of their brand. The communication designed by the marketing team at the corporate office of the pharmaceutical companies is used to communicate to doctors through MRs [3].

Unlike the personal selling of fast-moving consumer goods (FMCG) brands or durable consumer brands, MRs don't sell their products to patients. Patients or consumers pay for the prescription, and doctors control access to it. MRs increase product sales by influencing physicians to get prescribed more for their promoted brand [4].

India has 10,22,859 MBBS physicians registered with the MCI or State Medical Councils [5]. Thirty thousand registered pharmaceutical companies appoint more than 600,000 MR to cater to their promotional needs [2][6]. One Medical representative meets an average of 250 300 doctors in a month with a daily average of $10-12$ doctors. An MR needs to perform four essential tasks; detailing their products, monitoring the prescription and its sales, providing the sample, and making a retail booking. Even a slight improvement in the effect of any of these can significantly increase the results [7]

MR performs a very important task i.e detailing; the traditional sales of face-to-face detailing is still the most widely used marketing method [8]. In any form, personal or digital, proper detailing with visual aid is a very crucial marketing tool to increase the generation of prescriptions. With effective promotion and ongoing efforts, MR influences physicians to get their promoted brand on prescription [9].

Personal qualities like grooming, attitude, and communication are crucial tools to seek attention and create a positive impression in a doctor's mind. While professional qualities like detailing and scientific knowledge help for effective in-clinic discussion and build a good rapport with the doctor [10].

Hence it can be said that an MR should possess three qualities for an effective brand promotion viz. effective detailing, personal attire, and knowledge of the product can influence a doctor's prescription behavior. However, there is no literature available to quantify this relationship. Though present study, we tried to assess the impact of these three qualities of an MR that can influence the prescribing habits of a health care professional.

This highlights that MRs are the fundamental blocks of pharmaceutical marketing that meet the clinicians to influence their prescribing habits to get their promoted brands on prescription. In such intense competition, MRs need to show their supremacy over others to attract the attention of physicians. Several studies reported the influence of pharmaceutical marketing activities on doctors' prescribing behavior. Still, few have discussed a medical representative's personal and professional qualities who differ/implement such promotional tools with doctors.

Hence, this study aims to identify medical representatives' personal and professional qualities, which is important to attract physicians' attention. The study also tries to recognize that whether such personal/professional attributes of Medical representatives influence doctors' prescribing behavior or not.

\section{Materials and Method}

An exploratory, quantitative, cross-sectional research was performed using a descriptive survey to capture the real-world experience from the doctors practicing in Vadodara, Gujarat, India.

As per the Vadodara branch of the Indian Medical Association (IMA), 1926 healthcare practitioners are listed in Vadodara city, considered as the population for the study [11]. The sample value was 112 at a confidence level of $95 \%$ \& a margin of error of 0.09 . Sampling was done as per simple random sampling. Randomly 150 doctors were selected from the list of Vadodara city IMA members as a sample of the study.

Self-administered designed questionnaires were given to 150 doctors, mainly general practitioners, consulting physicians, dentists, pediatricians, and gynecologists through personal visits, email, or WhatsApp. The primary reason for selecting above mentioned specialties was as they cover a major portion of practicing doctors $(70 \%)$, and they write the majority of the prescription (72\%) [12].

\section{Study Model \& Hypothesis}

Based on a literature review, a hypothetical research model was established to explore the research objectives. The proposed correlation among the factors influencing (variables) the doctor's prescription behavior (outcome) is being narrated in Figure 1. Three hypotheses ( $\mathrm{H} 1, \mathrm{H} 2$, and H3) were made to observe the effect of variables on the outcome. 


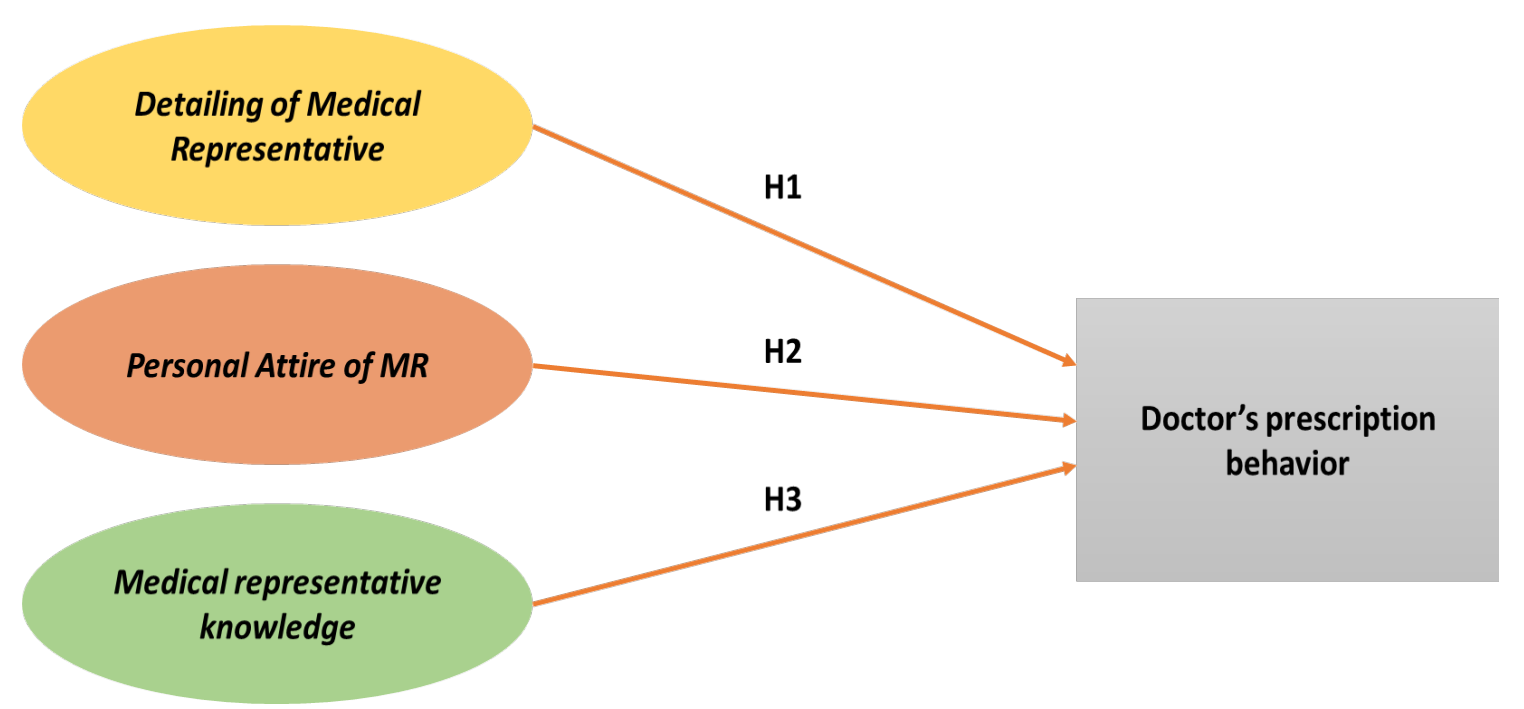

Figure 1. Proposed hypothesis in Research model

Null hypothesis (H0): Detailing, personal attire, and knowledge of MR do not influence a doctor's prescription behavior.

Hypothesis 1 (H1): Detailing of MR influences the clinician's prescribing behavior (Superior detailing and product promotion in a clinic, better prescription support from a doctor)

Hypothesis 1 (H2): Personal attire of MR influences the doctor's prescription behavior (A representative with good personal attire impacts a better company's image in doctor's mind)

Hypothesis 3 (H3): MR knowledge influences the doctor's prescription behavior (Physicians respect an MR with proper knowledge of the product)

Data validation was performed for unsatisfactory responses, such as for missing values and incomplete data. Incomplete and inappropriate questionnaires were removed, leaving 122 questionnaires suitable for data analysis. Out of 150 filled questionnaire, 19\% (28 questionnaires) was not filled appropriately. The majority of unappropriated responses were received via email, where the questionnaire was filled without guidance/supervision.

All the data were analyzed using the statistical package SPSS 22. Descriptive analysis was performed for all the independent variables to obtain the mean. Reliability and Validity Statistics were performed to obtain reliability coefficients and Cronbach alpha value. Cronbach alpha value of more than 0.6 was considered as passed. Multiple linear regression was performed to validate the model. Hypothesis Testing was done using ANOVA analysis. The level of significance was assessed at $5 \%$.

\section{Results}

Out of 122 doctors from various practicing specialties included general practitioners and dentists, together representing $48 \%$ of the sample, followed by consulting physicians, pediatricians, and gynecologists, representing $52 \%$ of the sample.

Table 1. Specialty pattern

\begin{tabular}{|c|c|c|}
\hline Specialty & Frequency & Percent \\
\hline General Practitioner & 30 & 25 \\
\hline Dentist & 28 & 23 \\
\hline Consulting Physician & 23 & 19 \\
\hline Paediatrician & 21 & 17 \\
\hline Gynaecologist & 20 & 16 \\
\hline Total & 122 & 100 \\
\hline
\end{tabular}

A 7-point Likert scale questionnaire was adopted in the study, based on which measurement structures have been established and tested for authenticity by reviewing the expert opinion \& literature. Reliability coefficient Cronbach alpha value exceeds the minimum value standard 0.6 for all measurement structures; overall, the reliability values of the questionnaire ranged from 0.77 to 0.81 .

Table 2. Reliability and Validity Statistics

\begin{tabular}{|c|c|c|c|}
\hline Construct & $\begin{array}{c}\text { Cronbach's } \\
\text { alpha }\end{array}$ & CR & AVE \\
\hline Detailing of MR & 0.78 & 0.75 & 0.61 \\
\hline Personal attire of MR & 0.81 & 0.79 & 0.57 \\
\hline MR's knowledge & 0.77 & 0.74 & 0.62 \\
\hline
\end{tabular}

CR: composite reliability; AVE: average variance extracted

Only high factor loadings (values greater than 0.6) were taken into consideration for the evaluation of the model. This study contributed $89 \%$ of the above factors and the materials used to measure structures were without cross-loading (Table 2). The results showed that the total reliability (CR) threshold value for all structures was 
greater than 0.7. The average variance extracted (AVE) value is also greater than the minimum value of 0.50 , which ensures the validity of the questionnaire tools.

\section{Data Variables and Measurement:}

The Mean summary statistics (Table 3) confirm the positive impact of medical representative personal quality like personality traits and attire and professional attributes like detailing and scientific knowledge. The knowledge of the medical representative shows high acceptance followed by detailing and then personal attire of medical representative.

Table 3. Mean summary for independent variables

\begin{tabular}{|c|c|}
\hline Independent Variables & Mean \\
\hline Detailing of medical representative & 5.3 \\
\hline Personal attire of medical representative & 4.7 \\
\hline MR's knowledge & 5.5 \\
\hline
\end{tabular}

Using the stepwise regression approach with three independent variables led to the model fit measurement of the multiple linear regression model (Table 5) for prescription behavior as a dependent variable; The $\mathrm{R}$-squared value is $70 \%$ and all the independent variables together affect the study variables individually. A sufficiently narrow $95 \%$ estimated interval S must be 2.5 . The $\mathrm{S}$ value is 0.533 , which ensures the accuracy of the model. The data show that doctors always appreciated the good personal \& professional qualities of medical representatives. The F-statistic is 26.7 , and the p-value is $<0.001$. The value of path coefficient, $\beta=0.27,0.17$, and 0.23 for detailing of medical representative, personal attire of MR, and medical representative's knowledge, respectively, at a p-value of $<0.05$. This implies that the results support the hypothesis. The accepted research hypotheses were not just accidental but a positive environment produced by these independent variables; therefore, the hypotheses were accepted and supported the positive impact of the independent variables on the physician's prescribing behavior. Ninety-two percent of doctors confirmed that MR with good therapeutic knowledge could better brand discussion in-clinic, leading to higher prescription support of the discussed brand. The data demonstrate the positive impact of the personal and professional qualities of MR on doctor's prescription behavior.

Table 4. Hypothesis Testing

\begin{tabular}{|c|l|c|c|c|c|c|}
\hline Variable & \multicolumn{1}{|c|}{ Hypothesis } & $\begin{array}{c}\text { t } \\
\text { Value }\end{array}$ & $\boldsymbol{\beta}$ & P-value & Direction & Decision \\
\hline Detailing of MR & $\begin{array}{l}\text { Superior detailing and product promotion in a clinic, better } \\
\text { prescription support from a doctor }\end{array}$ & 8.76 & 0.27 & 0.00 & Positive & Accepted \\
\hline $\begin{array}{c}\text { Personal Attire of } \\
\text { MR }\end{array}$ & $\begin{array}{l}\text { A representative with good personal attire impacts a better } \\
\text { company's image in doctor's mind }\end{array}$ & 5.40 & 0.17 & 0.00 & Positive & Accepted \\
\hline MR's Knowledge & $\begin{array}{l}\text { Physicians respect an MR with proper knowledge of the } \\
\text { product }\end{array}$ & 11.13 & 0.23 & 0.00 & Positive & Accepted \\
\hline
\end{tabular}

Table 5. Model Summary

\begin{tabular}{|c|c|c|c|c|}
\hline \multicolumn{5}{|c|}{ Model Summary } \\
\hline R & R Square & Adjusted R Square & Std. the error of the Estimate & ANOVA F (p-value) \\
\hline 0.76 & 0.577 & 0.572 & 0.533 & $26.7(0.000)$ \\
\hline
\end{tabular}




\section{Discussion}

The primary responsibility of an MR is to generate prescriptions from the registered medical practitioner through effective communication and brand promotion. Promotion-conversion-availability (PCA) model explains the process of doctor conversion. However, there is no scientific evidence for this model [13].

The first step in the PCA model is promotion, in which an MR performs using proper communication and impressive personality to promote their brands. MR can build a good rapport with the doctor through regular promotion and visits, making the conversion process the next step, i.e., doctor conversion. Scientific knowledge of medical representatives is very crucial in the doctor conversion step. Through effective discussion, once medical representatives influence doctors for their brand, the next step is to ensure the availability of their brand at the nearby retail counter to honor the prescription generated by the doctor. These three steps depict the journey of doctor conversion by MR starting from promotion to retail availability. To succeed at every step, the qualities of MR play a significant role, starting from personal attire, effective detailing, and scientific knowledge at the conversion stage (Figure 2). Many literatures narrate the significance of MR's qualities.

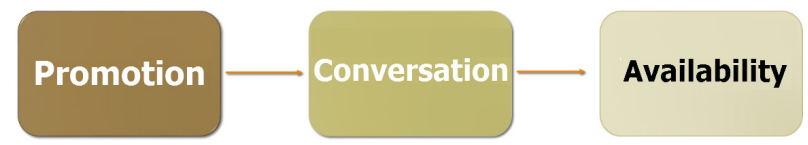

Figure 2. Promotion-conversion-availability model

\section{Medical representative detailing}

Detailing by an MR is a kind of personal selling, which comes under direct marketing. During detailing, an MR describes the brand, discusses the scientific points, and resolves the physician's query with a visual aid to persuade the physician and start getting prescriptions. [14] Other methods such as gifting, sponsoring Continuing Medical Education (CME), providing drug samples \& conferences participation are also adopted by MRs during the visit [15]. Singh et al. identified a conceptual model to understand the dual relation between MRs and physician prescribing. This addressed the three-dimensional model comprising network interconnection dimensions, resource transfer probability, successful integration, and circular actor relationships as predictors of action prescriptive medical professionals. The study concluded that when the interaction between MRs and doctors is strong, the correlation between product knowledge and prescribing behavior is robust [16]. In this digital age, with electronic detailing, in contrast to conventional information with written visual aids, MRs can speak more effectively about their products in the medical room [17]. The outcome of the study confirms that by supporting MR with to the point scientific information, he/she can persuade the physician to write promoted brands. MRs should be trained properly by pharmaceutical organizations to improve their scientific and product knowledge which helps them to have a good scientific discussion with doctors, and eventually helps doctors to recall brands while writing prescriptions.

\section{Personal attire / personality traits of medical representative}

The characteristics of personality represent the distinctive patterns of thought, feelings, and behaviors of individuals. Service employees and particularly the leading employees engage with customers to build a strong brand with their customers. The explanation is that consumer expectations of quality of service, corporate identity, and customer loyalty can influence frontline employees' attitudes, abilities, and actions [18]. There is evidence where the attire of employees can directly affect the customers' intent, which was proved in the present study. In a similar line, Shao et al. analyzed the relationship of personal attire on customers' expectations. The study showed that consumers are not only likely to judge their service workers by their clothing, but even all communications are likely to be proof of the nature of the service business itself [19]. Even this seems to be applicable for the pharmaceutical companies, too, where companies should focus on their MR's attire. We found that appropriately dressed MRs can contribute to higher satisfaction and a higher desire to prescribe their product than MR with improper attire.

Pharmaceuticals are essential goods; however, brand selection in prescription depends on many factors, and MR's attire and personality traits are among them. In agreement with to present study, Kasliwal et al. revealed that the promotional factors that were more influencing were the activities of MRs, their rapport with the doctors, and their personality traits [20]. The MR can positively impact good personality traits and attire, leading to physician prescription support. Doctors readily accept MR in such attire. Multinational and top-ranked Indian pharmaceutical companies used to specially train their MR on personal grooming. They don't want to ruin their reputation built-in doctors' minds with MR's behavior or attire. Small and mid-cap pharmaceutical companies should also work on the personal attire of MR if they want to get good reception from doctors and ready acceptance about their brands.

\section{MR's knowledge}

To attract the attention of customers is the major strategy in pharmaceutical marketing, but it requires backing up with scientific evidence. MRs are an important arm of drug marketing; therefore, they need to have the 
medical knowledge to have positive discussions with the clinician. Nowadays, doctors have been complaining about the quality of MRs visiting their hospitals. In the opinion of doctors, most MRs these days are just marketers, and only a few of them have in-depth knowledge on the subject and share updates about medications from time to time [17]. The World Health Assembly implemented the World Health Organization (WHO) ethical standards for the advertisement of medicinal drugs in 1988, which recommended that the MR should have a suitable academic qualification \& be trained. MR should provide information about drugs in an accurate, unbiased, and responsible manner with important medical and technical knowledge [21]. Ahmed et al. studied MR knowledge and its impact on doctors' prescribing behavior and reported a significant association between the two [13]. Pharmaceutical companies should select the appropriately qualified candidate as an MR and develop a suitable training course for the candidate with good scientific knowledge before connecting the field.

Kasliwal et al., in their study, found that the doctors with age between 41-45 years age were observed to get less influenced by the MRs personality, their product knowledge, and distribution of leaflets and brochures [20]. MR's product knowledge, relying upon the source of latest drug information from colleagues, has substantiated a positive effect on the youngest category of doctors (age between 25-35 years), while the foremost senior doctors within the age group of 61 and above years showed a positive behavior towards the materials distributed by the pharmaceutical companies in the form of leaflets and brochures.

Most pharmaceutical companies have a specialized training unit to train MRs to have better clinical discussions about the medical field, disease conditions, and brand benefits. Poor scientific knowledge about the brand or therapy not only damages the reputation of the MR but also spoiles the company's image in front of the doctor. The leading Indian companies \& MNCs limit access to MR with graduation in pharmacy or at least science. An MR with the right therapy/product information can easily persuade physicians for their brand than one with poor product/therapy knowledge MR. Companies should spend money to develop their MRs with proper scientific and product information to have a good negotiation with physicians, which eventually helps clinicians remember the product when writing prescriptions.

The present study is not devoid of limitations. The current study focuses only on personal qualities like the personality trait of MR and professional qualities like detailing and scientific knowledge of MR; more research requires to identify the influence of other qualities such as communication skills, negotiation skills, aptitude, strategy implementation etc., on doctor's prescription. To determine the effect of various personal and professional qualities of MR on physician's behavior, large-scale multicenter research is needed.

\section{Conclusions}

Pharmaceutical companies are always in a dilemma about their return on investments. Employees are the most significant asset for any organization, and investment in developing their abilities gives the highest returns. Medical representative is the crucial arm in pharmaceutical marketing, and investment done on MRs to build their personal and professional qualities can create a positive corporate image in doctor's minds, which turns into revenue through prescription generation. The study confirms the positive impact of MR's personal qualities like attire/personality traits and professional qualities like detailing and scientific knowledge on doctor's prescription behavior. High investment on field force, starting from the selection of the candidate to development through a formal training program and even after field joining through on job training and field development programs, can yield better in-clinic performance and thereby doctor conversion. Pharmaceutical marketing is all about a good relationship between doctor and MR; in such a case, medical representatives' personal and professional qualities play a significant role in the betterment of this association and prescription generation.

\section{Abbreviations}

MR: Medical Representative; MCI: Medical Council of India; FMCG: Fast-Moving Consumer Goods; MBBS: Bachelor of Medicine and Bachelor of Surgery; WHO: World Health Organization; CME: Continuing Medical Education

\section{Authors' Contributions}

KV contributed to the conception, design of the work, data analysis and interpretation, and drafted the work. SaS substantially contributed to the data analysis and work revision. SeS contributed to supervision and validation of work. All authors have read and approved the manuscript.

\section{Funding}

The authors received no specific funding for this work.

\section{Competing Interests}

The authors have declared that no competing interests exist. 


\section{REFERENCES}

[1] F. Fahimi, "How Medical Representatives Influence Prescribers Behavior?," Iran. J. Pharm. Res., vol. 11, no. 2, pp. 383-384, 2012.

[2] K. Bala and K. Sharma, "Role of Medical Representatives in Influencing Medicine Prescription Behaviour of Doctors," J. Bus. Thought, vol. 10, no. April 2019, pp. 39-52, 2019.

[3] C. Lee Ventola, "Direct-to-Consumer Pharmaceutical Advertising Therapeutic or Toxic?," P T, vol. 36, no. 10, pp. 669-684, 2011.

[4] A. Fugh-Berman and S. Ahari, "Following the script: How drug reps make friends and influence doctors," PLoS Med., vol. 4, no. 4, pp. 621-625, 2007.

[5] R. Kumar and R. Pal, "India achieves WHO recommended doctor population ratio: A call for paradigm shift in public health discourse!," J. Fam. Med. Prim. care, vol. 7, no. 5, pp. 841-844, 2018.

[6] R. R. Kesireddy, "Pharma firms like Pfizer and others replace medical representatives with new age executives," Editor, The Economic Times, 2015. [Online]. Available: https://economictimes.indiatimes.com/industry/healthcare/ biotech/pharmaceuticals/pharma-firms-like-pfizer-and-othe rs-replace-medical-representatives-with-new-age-executive s/articleshow/46751863.cms?from $=$ mdr. [Accessed: 24-Oct-2020].

[7] C. Ankush et al., "A Survey on Doctor's Expectation From Medical Representative In Karnataka State," Int J Cur Res Rev, vol. 7, no. 8, pp. 75-82, 2015.

[8] E.-S. Kwak and H. Chang, "Medical Representatives' Intention to Use Information Technology in Pharmaceutical Marketing," Healthc. Inform. Res., vol. 22, no. 4, p. 342, 2016.

[9] L. Kumar and A. Panigrahi, "Communication with Doctors: Empowering Pharma Field Force With Modern Marketing Techniques," Asian J. Manag. Res., vol. 5, no. 2, pp. 191201, 2014.

[10] Prof. Ajay Gidwani, “ASSESSMENT OF DOCTOR'S PERCEPTION TOWARDS MEDICAL REPRESENTATI

VES," INDIAN J. Res., no. 11, pp. 11-16, 2018.

[11] I. M. Association, "About Indian Medical Association, Vadodara," IMA Vadodara, 2010. [Online]. Available: http://www.imavadodara.org/index.php?option=com conte nt\&view=article\&id=132. [Accessed: 25-Oct-2020].

[12] IMS, “IPM Company Standing IMS Rx Dec'19.” 2019.

[13] R. R. Ahmed, "Pharmaceutical marketing mix strategy and physician's prescription behavior," Pharma Innov., 2014.

[14] B. K and F. UK, "Influence of Pharmaceutical Marketing on Prescription Behavior of Physicians: A Cross-sectional Study in Bangladesh," J. Account. Mark., vol. 5, no. 2, pp. $2-5,2016$.

[15] D. A. D. Dr Arun Gadre, "Promotional Practices of the Pharmaceutical Industry and Implementation Status of Related Regulatory Codes in India," Support Advocacy Train. to Heal. Initiat., p. 72, 2019.

[16] R. Singh, "Network connectedness of pharmaceutical sales rep (FLE)-physician dyad and physician prescription behaviour: A conceptual model," J. Med. Mark., vol. 8, no. 3, pp. 257-268, 2008.

[17] P. Bhatt, "Study on Influence of Medical Representative in Conversation of Doctor's Prescription in India," Glob. Journals Online Glob. J. Manag. Bus. Res., vol. 18, no. 3, 2018.

[18] Y. Ekinci and P. L. Dawes, "Consumer perceptions of frontline service employee personality traits, interaction quality, and consumer satisfaction," Serv. Ind. J., vol. 29, no. 4, pp. 503-521, Apr. 2009.

[19] C. Y. Shao, J. A. Baker, and J. Wagner, "The effects of appropriateness of service contact personnel dress on customer expectations of service quality and purchase intention," J. Bus. Res., vol. 57, no. 10, pp. 1164-1176, Oct. 2004.

[20] N. Kasliwal and I. Bansal, "Influence of pharmaceutical promotional tools on doctors' prescribing behaviour: An exploratory study," Indian J. Mark., vol. 43, no. 8, pp. 2334, 2013.

[21] N. T. Jacob, "Drug promotion practices: A review," British Journal of Clinical Pharmacology, vol. 84, no. 8. pp. 1659 1667,2018 